DOI 10.37882/2223-2982.2021.11-2.04

\title{
ПРАГМА-СЕМАНТИЧЕСКИЕ ОСОБЕННОСТИ СЛОВА-АРГУМЕНТАТОРА «STILL» В НАУЧНОМ ДИСКУРСЕ КРИТИКИ
}

\section{PRAGMA-SEMANTIC FEATURES OF THE ARGUMENTATIVE WORD "STILL" IN THE SCIENTIFIC DISCOURSE OF CRITICISM}

N. Barebina V. Semenova

Summary: The article is devoted to the role of the word STILL in the function of the argumentative word in English. The empirical material is presented in a corpus of examples of critical reviews of scientific works in the subject areas of applied linguistics. The article analyzes the pragmatic and semantic features of the STILL lexeme in the formation of the criticism argument. This lexeme is analyzed in the context of the categories of text coherence and in the light of data on the linguistic status of the argument words. The argumentative mechanism of orientation in the secondary deixis is shown.

Keywords: argumentation, anaphora, deixis, criticism, words-arguments.

\author{
Баребина Наталья Сергеевна \\ Д.филол.н., дочент, Байкальский государственный \\ университет \\ svire123@rambler.ru \\ Семенова Вера Владимировна \\ Аспирант, Байкальский государственный университет \\ 7_ew@mail.ru
}

Аннотация: Статья посвящена роли лексемы STILL в функции слова-аргументатора в английском языке. Эмпирический материал представлен корпусом примеров критических обзоров и рецензий на научные работы по предметным областям прикладной лингвистики. В статье анализируются прагматические и семантические особенности лексемы STILL в формировании аргумента критики. Данная лексема, проанализирована в контексте категорий связности текста и в свете данных о лингвистическом статусе словаргументаторов. Показан аргументативный механизм ориентирования во вторичном дейксисе.

Ключевые слова: аргументация, анафора, дейксис, критика, слова-аргументаторы.

жат средством усиления или изменения аргументативной силы высказывания [8].

Современные разработки в рамках этого направления [5; 6] придают этим коннекторам особый статус и анализируют их в терминах «слова-аргументаторы», «аргументативные коннекторы», «слова-индикаторы» и показывают, что их аргументативный статус позволяет «интерпретировать высказывание как аргумент для некоторого заключения, часто имплицитного, являющегося целью говорящего» [6, с. 492]. Значимым является и анализ возможных пресуппозиций. В английском языке примерами таких единиц являются лексемы still, however, even, yet.

В ходе исследования использовался метод реферирования текстового целого, контекстуальный анализ. Выборка представляет собой примеры фрагментов текстов научных рецензий, содержащих оценку. В анализе мы задействовали результаты исследований, в которых указанные единицы рассматриваются как грамматические категории и в которых анализируются их семантические и синтаксические особенности [4; 3]. Обратимся к анализу примеров со словом still.

1. In the field of teaching the Chinese language to foreign learners (TCFL hereafter) in China, form-centered teaching still dominates the nation's classrooms, despite the 
fact that the majority of students studying in China are there for communicative fluency [11]. В примере still в функции слова-аргументатора имеет эмоциональное значение «удивление», «неожиданность» и «длительность». Предлог despite соединяет части сложного предложения и передает контраст, в данном примере мы видим, что still усиливает контраст и смещает внимание к первой части предложения. Пресуппозиция имеет вид «вопреки ожиданию»: Оказывается, что в Китае до сих пор преобладает формально ориентированное обучение китайскому иностранных студентов, несмотря на запрос к коммуникативной беглости. При этом член синтагмы, к которой относится still, становится более значимым (dominates). Возникает отношение антитезы, где очевидно резкое противопоставление двух ситуаций

Рассмотрим еще пример.

2. The chapter concludes by stating that while there has been a large amount of research into metaphonological skills and influence on speech production, there is still much to understand about how metaphonological processing may differ across languages with different phonological systems [9].

Слово-аргументатор still формирует отношение асимметрии: содержание первой части бессоюзного предложения приобретает малое значение по сравнению со второй частью, где необходимо еще много и долго осмысливать то, как метафонологическая обработка может отличаться в разных языках с разными фонологическими системами. Слово-аргументатор still участвует в формировании фигуры восходящей градации. Рассмотрим еще пример.

3. Only one chapter explicitly offers information about an information search protocol in terms of databases sourced to inform the chapter content, although this still only accounts for a small portion of the chapter (Chapter 16 on Brazilian Portuguese) [9]. В примере лексема still стоит в постпозиции к союзу although, который, как известно, выражает противоречие. Однако still выражает в данном случае дополнительное значение противоречия между тем, что ожидалось и фактом действительности. Заметна реализация временного отношения длительности. Как видим, слово still усиливает союз although в противоречии и формирует семантику «неоправданное ожидание».

Пресуппозиция, связанная с нежелательным действием, но которое до сих пор не изменилось, формируется в следующем примере:

4. However, it is left unspecified what the authors mean precisely by 'intensity': whether we are speaking about some prosodic metrics or somebody's perception. It is more likely to be the latter, since the authors use the words 'contrast is felt even stronger', but it still remains unclear whether the decisions are based on the authors' personal intuitions or on the results of some perception study [10].

В этом предложении слово-аргументатор still, как и в примерах (1) и (3), репрезентирует противоречие, но дополнительно акцентирует внимание на недостатке научной работы: «все еще остается неясным...».

Рассмотрев семантические и прагматические аспекты слова-аргументатора still в научных текстах критики, можно заключить, что этот аргументативный коннектор, имея значение противопоставления, длительности, акцентирования, выделяет слово в синтагме, к которой оно относится: still dominates, still much to understand, still only accounts, still remains. Следует отметить, что данная лексема также и уточняет лексическое значение связанных с ней слов. Следовательно, данная лексема в функции слова-аргументатора представляет механизм усиления аргументативной силы.

Наблюдения над языковым материалом позволили сделать еще некоторые выводы относительно сложного предложения. Та часть сложного предложения, которая содержит лексему still в качестве показателя отношения противоречия, всегда находится в постпозиции.

Если соотнести данные наблюдения с выводами французских лингвистов в рамках направления «Радикальный аргументативизм», о котором шла речь в начале статьи, то прослеживается роль коннектора still в аргументативной ориентации - вывод содержится во второй части сложного предложения, тогда как первая часть представляет собой некоторую причину для критики. В терминах категорий связности текста это можно выразить через соотношение дейксиса и анафоры. Это дает некоторое объяснение для явления вторичного дейксиса. Б.А. Успенский пишет, что в ситуации вторичного дейксиса имеет место ориентация на речевую позицию говорящего или пишущего «как производителя речи» и что «соотнесение с речевым актом осуществляется при этом через какую-то промежуточную инстанцию, которая, в свою очередь, либо опосредованно соотносится с говорящим или, в более общих терминах, с создателем текста как реальным лицом, либо выступает как субститут говорящего, имитируя его поведение» [7, c. 11]. В этом случае still служит маркером анафорического употребления слова в синтагме для указания на некоторое условие, о котором шла речь ранее и указывает на направление аргументативной ориентации от причины к выводу. Далее считаем важным исследовать роль данной лексемы в других значениях с точки зрения изменения аргументативной силы. 


\section{ЛИТЕРАТУРА}

1. Баребина Н.С. Интерпретационный компонент аргументативных конструкций критики в англоязычных рецензиях как экспликация оценки в научном дискурсе / Н.С. Баребина, М.И. Тагиев, С.А. Тигунцев // Филологические науки. Вопросы теории и практики, 2020. Т. 13. № 9. С. 181-186.

2. Баребина Н.С. Лингвоаргументативный анализ критики в научной экспертизе (на материале текстов рецензий на лингвистические работы) / Н.С. Баребина, И.Н. Зырянова // Филологические науки. Вопросы теории и практики. 2019. № 11. С. 335-342.

3. Горбачева 0.А. Дифференциация значений полисемантичного союза and: дисс. . .. канд. филол. н. / 0.А. Горбачева. М., 2005. 167 с.

4. Лунина 0.А. Выражение отношений противоречия в сложных предложениях: дисс. ... канд. филол. н. / О.А. Лунина. Воронеж, 2001.136 с.

5. Нешева Т.В. Коммуникативно-прагматический потенциал слов-аргументаторов // Концептуальная систематика аргументации / Г.М. Костюшкина, А.В. Колмогорова, Н.С. Баребина, С.Ю. Дашкова, Е.О. Ильичева [и др.] / под ред. Г.М. Костюшкиной. М.: ФЛИНТА, Наука, 2016. С. 390-481.

6. Ситосанова 0.В. Семантика и прагматика слов-аргументаторов в бытовом дискурсе // Концептуальная систематика аргументации / Г.М. Костюшкина, А.В. Колмогорова, Н.С. Баребина, С.Ю. Дашкова, Е.О. Ильичева [и др.] / под ред. Г.М. Костюшкиной. М.: ФЛИНТА, Наука, 2016. С. 482-538.

7. Успенский Б.А. Дейксис и вторичный семиозис в языке / Б.А. Успенский // Вопросы языкознания. 2001. №2. С. 3-30.

8. Ducrot, 0. Analyses pragmatiques / 0. Ducrot // Communications, 1980. P. 11-60.

9. Plant Ch. Review / Ch. Plant. - URL : (дата обращения 12.10.2021). - Review of book : Review of Motor Speech Disorders / N. Miller, A. Lowit. - Bristol : Channel View Publications Ltd, 2014.

10. Traat M. Review / M. Traat. - URL: (дата обращения 12.10.2021). - Review of book: Review of Information Structure / A. Steube. - Bristol : De Gruyter Mouton, 2004.

11. Young Sh.-J.J. Review / Sh.-J. J. Young. - URL: (дата обращения 12.10.2021). - Review of book : Review of Cover Foreign Language Teaching in Asia and Beyond / W.M. Chan, K.N. Chin. Boston : De Gruyter Mouton, 2011.

( Баребина Наталья Сергеевна (svirel23@rambler.ru), Семенова Вера Владимировна (7_ew@mail.ru).

Журнал «Современная наука: актуальные проблемы теории и практики»

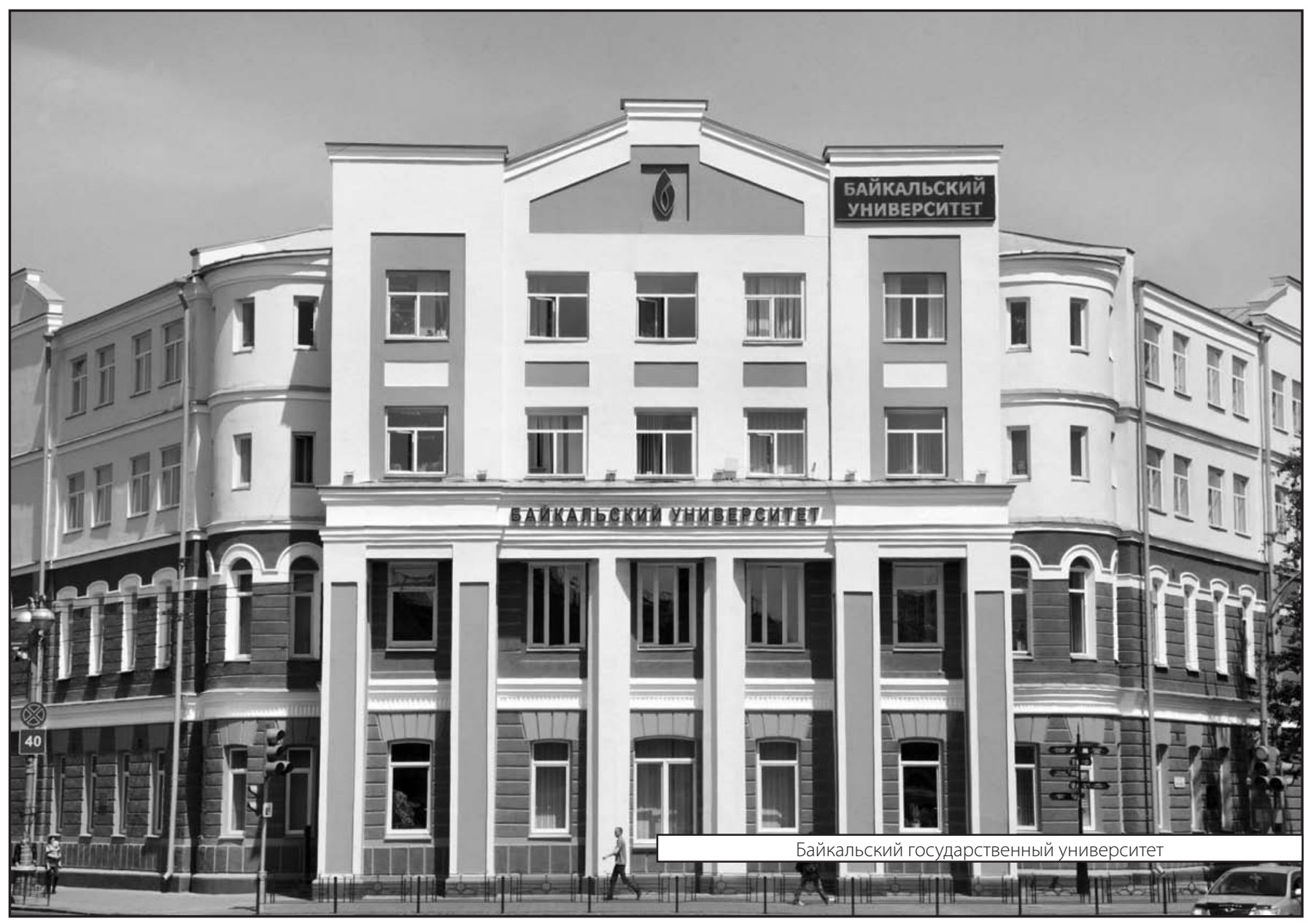

